Please do not remove this page

RMIT

UNIVERSITY

\title{
Embedded flaws for crack path control in composite laminates
}

Orifici, Adrian; Wongwichit, Phisit; Wiwatanawongsa, Nuth

https://researchrepository.rmit.edu.au/esploro/outputs/9921862134001341/filesAndLinks?institution=61RMIT_INST\&index=null

Orifici, A., Wongwichit, P., \& Wiwatanawongsa, N. (2014). Embedded flaws for crack path control in composite laminates. Composites Part A: Applied Science and Manufacturing, 66, 218-226.

https://doi.org/10.1016/j.compositesa.2014.08.012

Document Version: Accepted Manuscript

Published Version: https://doi.org/10.1016/j.compositesa.2014.08.012

Repository homepage: https://researchrepository.rmit.edu.au

(C) 2014 Elsevier Ltd.

Downloaded On 2023/04/26 16:47:27 +1000

Please do not remove this page 
Thank you for downloading this document from the RMIT Research Repository.

The RMIT Research Repository is an open access database showcasing the research outputs of RMIT University researchers.

RMIT Research Repository: http://researchbank.rmit.edu.au/

\section{Citation:}

Orifici, A, Wongwichit, P and Wiwatanawongsa, N 2014, 'Embedded flaws for crack path control in composite laminates', Composites Part A: Applied Science and Manufacturing, vol. 66 , pp. 218-226.

See this record in the RMIT Research Repository at:

https://researchbank.rmit.edu.au/view/rmit:29909

Version: Accepted Manuscript

Copyright Statement: (c) 2014 Elsevier Ltd. Creative Commons Attribution-NonCommercial NoDerivatives 4.0 International License.

Link to Published Version:

http://dx.doi.org/10.1016/j.compositesa.2014.08.012 


\title{
Embedded flaws for crack path control in composite laminates
}

\author{
Adrian C. Orifici ${ }^{a}{ }^{*}$, Phisit Wongwichit ${ }^{a}$ and Nuth Wiwatanawongsa ${ }^{a}$ \\ ${ }^{a}$ RMIT University, School of Aerospace, Mechanical and Manufacturing Engineering, \\ GPO Box 2476, Melbourne, Victoria 3001, Australia \\ * corresponding author: adrian.orifici@rmit.edu.au, +61 39925 6092, fax +61 399256108
}

\begin{abstract}
An experimental investigation was conducted on using small flaws purposefully introduced into composite laminates to control growth of interlaminar cracks and throughthickness crack branching. Mode I crack growth specimens were used to study branching through $0^{\circ}, 90^{\circ}$ and $45^{\circ}$ plies. The results showed that crack growth through $0^{\circ}$ plies could be promoted by a ply gap, but this was not as controllable as combining a ply gap with a pre-crack to create a "crack branch flaw”. Crack branching through $45^{\circ}$ plies could be controlled using crack branch flaws, and also promoted controllably using ply gaps. Crack branching through $90^{\circ}$ plies was seen without any flaws, but was better controlled with embedded delaminations. Using these outcomes, crack branching through two quasiisotropic laminates was demonstrated. The results have application to improved damage tolerance and fracture toughness, by taking advantage of high toughness crack growth mechanisms.
\end{abstract}

Keywords: A. Laminates; B. Delamination; B. Fracture; D. Mechanical testing 


\section{Introduction}

Natural materials such as wood and bone can demonstrate high toughness crack growth mechanisms such as crack deflection and crack bifurcation. These mechanisms are the result of the interaction of the growing crack with the underlying material microstructure, which occurs at several length scales. These microstructural features are commonly in the form of weak links or pathways with low toughness, or alternatively a microstructure that promotes crack diffusion or delocalisation [1-4]. Recent advances in bio-inspired material design have seen these features exploited to improve the toughness of fibre-reinforced composite [5], glass [6, 7], ceramics [8] and any soft material with a brittle reinforcement [9].

Crack growth in fibre-reinforced composite laminates typically occurs along ply interfaces, due to the relatively weak interlaminar bond strength. Crack diffusion in this context requires the crack to "branch" or deflect into a ply, and is dependent on the orientation and nature of the plies bounding the crack interface. Crack branching is a common feature of impact damage [10], and is common in crack growth $[11,12]$. However, the occurrence of crack branching in this manner is uncontrolled, and only limited work [13] has been published on attempting to specifically generate this type of behaviour. This lack of knowledge prevents the application of biomimetic crack growth principles to control crack branching in composite laminates.

Controlling the initial crack location within a composite laminate is commonly achieved with the use of a non-adhesive thin film inserted between plies during lay-up. One issue with this is the creation of a resin-rich region at the edge of the inclusion [14]. This 
region has its own fracture properties, which can be problematic as it makes the inclusion less representative of a delamination occurring from in-service operation. Despite this, the use of an inclusion to generate a pre-existing flaw within the laminate has clear potential as a crack control mechanism for composite laminates. However, the use of a series of flaws away from the crack tip for continual control of the crack path has not been rigourously studied.

Numerous authors have studied the problem of a pre-existing delamination in a composite laminate, bounded by plies of various orientations $[11,15,16]$. Standards for interlaminar crack growth [17] prescribe the use of unidirectional laminates, so that the crack remains in the original interface between $0^{\circ}$ plies. For cracks between plies of different orientation, a wide range of results have been reported in literature. However, these studies are conducted with a focus on material characterisation and not crack path control. As a result, crack growth behaviour typically shows considerable variability, and different researchers investigating the same configurations have reported conflicting results [11]. So, there is a need to systematically study and further understand how the crack path can be reliably controlled through different ply configurations.

Recently, Malkin et al. [13] looked at crack growth in a unidirectional laminate under bending, which is characterised by catastrophic fibre failure in the through-thickness direction. They used gaps in the ply layers to mimic the microstructure of nacre, and achieved progressive failure by controlling crack growth to occur through the ply interfaces and ply gaps. This work represents an important step in applying biomimetic crack growth concepts to composite laminates. It also demonstrates the use of a series of embedded flaws 
and an understanding of weak planes in the laminate to continually control the crack path. However, only a unidirectional laminate was studied, and crack growth through different ply orientations was not considered. Also, the flexural loading investigated generates varying stress distribution through the laminate and different conditions at each of the ply gap regions. Further, the influence of the different fracture properties of the resin-rich region was not considered, as this was not relevant within the context of the specimens and crack behaviour studied.

In this work, different embedded flaw types are investigated for crack branching control through various ply orientations. A wide range of flaw configurations are investigated using a mode I crack growth specimen. Different laminates are used to investigate the crack branching problem through the ply angles of a quasi-isotropic laminate. Delamination flaws and ply gaps are studied, and a new type of flaw that combines a ply gap with a pre-crack is introduced and investigated. The results represent comprehensive demonstration of embedded flaws as an effective crack control device for all quasi-isotropic ply angles. The lessons learnt from these studies are then applied to demonstrate crack path control in typical quasi-isotropic laminates.

\section{Specimen definition}

The experimental analysis in this work focused on mode I interlaminar crack growth using the Double Cantilever Beam (DCB) specimen, according to the ISO Standard [17]. The specimen design is a unidirectional laminate with a central pre-crack that is loaded in mode I opening to force the crack to propagate along the mid-plane. This specimen was modified to investigate different laminate combinations, and different embedded flaws. The 
nominal specimen geometry is shown in Figure 1. Variations in ply angles considered only the angles of typical aerospace quasi-isotropic laminates, that is, $0^{\circ}, 45^{\circ}$ and $90^{\circ}$. The specific laminates investigated are presented in Table 1. All specimens used unidirectional carbon/epoxy VTM-264 prepreg composite plies, with nominal cured ply thickness 0.22 mm. Most specimens used "pre-cracking" to grow the crack from the initial location, though crack path behaviour was found to be the same with and without pre-cracking, so that for some specimens pre-cracking was not used. At least five specimens were tested for each configuration. An Instron $10 \mathrm{kN}$ test machine and load cell was used, with specimens loaded in displacement control.

A range of embedded flaw types were investigated. All specimens contained an initial starter crack in the mid-plane at the specimen edge, in accordance with the standard [17]. This was generated using a full-width strip of non-adhesive film that was included between the two centremost plies during the layup process. Two different non-adhesive films were used interchangeably (25 $\mu \mathrm{m}$ and $13 \mu \mathrm{m}$ ethylene-tetrafluoroethylene (ETFE)), due to varying availability within the manufacturing laboratory. Repeat specimens were used to confirm that the behaviour using either film was suitably similar. Additional "delamination flaws” were generated by including non-adhesive strips in a similar manner at various locations away from the crack tip. "Ply gap” flaws were created by laying a ply down in two parts, with a small $(1 \mathrm{~mm})$ gap that filled with resin during curing, as shown in Figure 2. Based on the results of the investigation as it progressed, a new type of flaw was developed and investigated. A “crack branch" flaw was created by laying one part of the ply down, placing a non-adhesive strip in the ply gap region, then laying the second part of 
the ply down to complete the ply, as shown in Figure 2. This created a flaw that combined a ply gap with a pre-existing crack that traversed the ply gap region.

The experimental investigation considered four main focus areas: (1) Crack branching through a $0^{\circ}$ ply; (2) Crack branching through a $90^{\circ}$ ply; (3) Crack branching through a $45^{\circ}$ ply; (4) Crack branching through a quasi-isotropic laminate. A summary of the specimens investigated is presented in Table 1 . Specimens were labelled according to the crack branching that was being studied, where specimens 0-i to 0-iii were used for branching through $0^{\circ}$ plies, specimens 90 -i to 90 -v for $90^{\circ}$ plies, specimens 45 -i to 45 -vi for

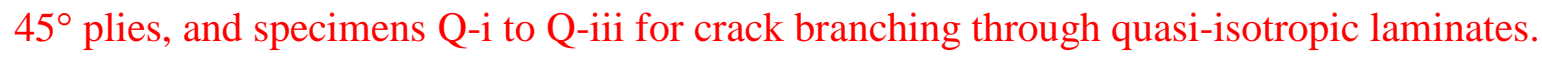
In Figure 3 the various flaw configurations are shown, where some specimens used the same flaw configuration with a different laminate. In Table 1, the flaw locations are identified using ply numbers, where branch flaws and ply gaps refer to the ply that is being branched or cut, and delamination (delam) flaws are reported using the two bounding plies (e.g. "ply 7-8" is the interface between plies 7 and 8). The distance from the edge of the initial flaw to the first embedded flaw (behind the crack tip) was $10 \mathrm{~mm}$ for all specimens unless otherwise indicated. It was considered that a $10 \mathrm{~mm}$ distance was sufficient as the focus was on crack patterns, and not on avoiding any influence of the feature on the stress state at the initial flaw. Similarly, although crack jumps of $10 \mathrm{~mm}$ could potentially occur from the initial flaw, this was not considered to have any effect on the resultant crack pattern. Delamination flaws and crack branch flaws were $10 \mathrm{~mm}$ in length for all specimens except Q-i to Q-iii where lengths of $5 \mathrm{~mm}$ were used. Further detail on the individual 
specimens in each of the four focus areas is presented as part of the discussion on experimental results.

\section{Experimental results}

Experimental results are presented as a schematic illustrating the typical crack growth pattern (crack path) and a representative graph of the applied load $(P)$ versus applied displacement $(\delta / 2)$. Crack growth schematics are always shown with the initial crack at the left specimen edge and crack growth from left to right. The crack growth patterns are supported by optical microscopy of the specimen edge, which are similarly presented with the crack growing from left to right. Crack growth schematics are a simplified representation of the crack path, and show the crack path as a single line consisting of mostly straight segments. The real crack growth patterns, as shown in the optical microscopy images, often show wavy crack paths and multiple cracks. The combination of the crack pattern, microscopy images and the load-displacement behaviour of the specimen provide the most useful results to assess the crack control techniques. For the loaddisplacement results the scales of the axes are removed for clarity, though in general the peak force for all specimens ranged from $40 \mathrm{~N}$ to $60 \mathrm{~N}$, and the maximum applied displacement ranged from $30 \mathrm{~mm}$ to $80 \mathrm{~mm}$.

The strain energy release rate $(G)$ was calculated for each specimen according to the “Corrected Beam Theory” method in the standard [17]. The crack length was determined from the painted (front) edge of the specimen. As such, this did not account for situations where a non-straight crack front was seen, though the standard does not cover this aspect, and the outcome did not affect the focus of the work on crack control behaviour. A 
summary of $G$ results are presented in Table 1, where values are presented for the initiation of crack growth $\left(G_{\text {init }}\right)$ and the average of all calculated points during the entire crack growth $\left(G_{\text {avg }}\right)$. These values were calculated at points in the loading of visually observed crack growth ("VIS points" according to the standard [17]). Values are provided with the coefficient of variation (COV) (standard deviation divided by average) in parentheses.

These results are presented as a reference only, as they do not provide much useful information with regards to crack control behaviour, due to the different number and type of embedded flaws across specimens, the crack path moving away from the mid-plane and the varying degree of fibre bridging. For the same reasons, the work of fracture (area under the applied load-displacement curve) was not calculated, and the R-curve (fracture toughness vs crack length plot) is not presented, as the focus of the work was on studying crack control behaviour.

\subsection{Crack branching through a $0^{\circ}$ ply}

Crack branching through a $0^{\circ}$ ply was investigated primarily with specimens 0 -i to 0 iii as shown in Table 1 and Figure 3. The standard unidirectional laminate DCB specimen (Specimen 0-i) has the crack growth direction aligned with the fibres, so that the initial crack is at a $\left[0^{\circ} / 0^{\circ}\right]$ interface and bounded by $0^{\circ}$ plies on either side. Crack branching in this situation would require fracture of fibres in one of the bounding $0^{\circ}$ plies. As the energy to break the interlaminar bond between the plies is much less than the energy for fibre fracture, the crack remains within its original location as it propagates along the specimen length. This is shown in Figure 4(a). 
To generate a branch through a $0^{\circ}$ ply it is clear that some break in the continuous $0^{\circ}$ ply is needed. Specimens with a ply gap flaw were investigated (Specimen 0-ii), and results are summarised in Figure 4(b). The use of ply gaps was found to be able to generate crack branching through a $0^{\circ}$ ply. However, there were two key aspects of this behaviour. The first is that the resin-rich zone that exists in the ply gap is actually a region of increased toughness. The fracture toughness of the resin was not found in literature and the neat resin was not available for purchase from the supplier. However, results from unidirectional $0^{\circ}$ specimens (Specimen 0-i) showed that the fracture toughness associated with crack growth from the edge of the non-adhesive film insert was on average around 2.5 times higher than that from a "natural" crack generated from pre-cracking. So, for a ply gap flaw, when the crack reached the resin-rich region, crack growth was delayed and the load increased until fracture through the resin could occur. This can be seen in the peaks in the loaddisplacement behaviour. The second aspect of crack growth with a ply gap was that the crack did not always branch through a ply gap region. Further, specimens with a series of ply gaps in a unidirectional laminate showed that once a crack branched through a ply gap, it would not return to the original interface if it passed through another ply gap region. Both of these aspects make the use of ply gaps for reliable control of crack branching through $0^{\circ}$ plies unsuitable, as they demonstrate a lack of consistency and lack of control of the crack path.

To overcome the unsuitable nature of ply gaps for crack branching through $0^{\circ}$ plies, the use of a crack branch flaw was investigated (Specimen 0-iii). The results are summarised in Figure 4(c), and a sample crack pattern as observed from the specimen edge 
is shown in Figure 5. The use of the branch flaw was shown to be highly effective in generating a crack branch, in a consistent and controllable manner. The crack always passed through the branch flaw from one ply interface to the other. However, crack branching through a branch flaw was also associated with large drops in load and low fracture toughness.

\subsection{Crack branching through a $90^{\circ}$ ply}

Crack branching through a $90^{\circ}$ ply was investigated primarily with specimens $90-i$ to 90-v as shown in Table 1 and Figure 3. Specimens used laminates with $0^{\circ}$ and $90^{\circ}$ plies, where the initial crack was located within a $\left[0^{\circ} / 90^{\circ}\right]$ interface. For these specimens (Specimen 90-i), crack branching was found to occur immediately upon the initiation of crack growth. This is expected as in $90^{\circ}$ plies the fibres are transverse and perpendicular to the proposed crack growth direction, and as such present an easy path for crack branching through only matrix material. The crack branching angle varied from $60^{\circ}$ to $90^{\circ}$, with reference to the initial interface. For some specimens, cracks that branched from the initial interface to the other side of the $90^{\circ}$ ply subsequently saw crack branching back to the original interface, such that a continual zig-zag pattern was observed. However, this was not consistent, and it was more common for a crack to continue along the same interface once it had initially branched away from the initial interface. This is shown in Figure 6(a). Other researchers investigating similar configurations have seen a consistent zig-zag pattern $[15,16]$. This suggests that the behaviour seen in this work is related to the relative fracture toughness of the $0^{\circ} / 90^{\circ}$ interface and the matrix, rather than the altered stress state at the crack tip caused by the crack being offset from the specimen mid-plane. A consistent zig- 
zag pattern was generated for crack branching through two $90^{\circ}$ plies (Specimen 90 -ii), with crack propagation segments of approximately $0.92 \mathrm{~mm}$ connected by crack branches at around $45^{\circ}$ through the ply. This is shown in Figure 6(b) and in Figure 7.

Specimens were investigated with a sequence of delamination flaws from embedded non-adhesive strips that were spaced along the central $\left[0^{\circ} / 90^{\circ}\right]$ interface. The results of these are summarised in Figure 6(c). These specimens showed that a delamination flaw was able to consistently attract the crack back to the initial interface. This demonstrates a further crack control technique for crack branching through $90^{\circ}$ plies. Specimens were investigated with $10 \mathrm{~mm}$ spacing between delamination flaws (Specimen 90-iii) and $20 \mathrm{~mm}$ spacing between delamination laws (Specimen 90-iv), and very similar results were seen, demonstrating no influence of the delamination flaw length. For specimens with two central $90^{\circ}$ plies (Specimen 90-v), the use of delamination flaws disrupted the zig-zag pattern seen without flaws, and in general an uncontrolled and variable crack pattern was seen.

\subsection{Crack branching through a $45^{\circ}$ ply}

Crack branching through a $45^{\circ}$ ply was investigated primarily with specimens 45 -i to 45-vi as shown in Table 1 and Figure 3. Similar to the situation for $90^{\circ}$ plies, for an initial crack at a $\left[0^{\circ} / 45^{\circ}\right]$ interface (Specimen $45-\mathrm{i}$ ), crack branching was seen to occur immediately upon initiation of crack growth. However, instead of a simple vertical crack, a more complex crack pattern was observed. Firstly, the crack often took a more torturous path through the middle of the $45^{\circ}$ ply, and multiple crack paths were seen within the same ply. This was reflected in increased fracture toughness in propagation, seen in higher $G_{a v g}$ 
values. Further, the crack branching occurred at $45^{\circ}$ across the width of the specimen, that is, in plan view (or the XY plane with reference to Figure 1) the line of crack branching was at $45^{\circ}$ to the initially straight crack front. This meant that on one side of the specimen (the "front" as viewed with the initial crack on the left, or $y=-B / 2$ with reference to Figure 1) crack branching was seen from the edge of the initial crack, whilst on the other side of the specimen (the "rear”) the crack propagated along the initial interface until it reached a point where it intersected with $45^{\circ}$ fibres that started on the other edge. This is shown in Figure 8(a), where both front and rear side crack paths are shown, and the progression of the crack front from straight to a $45^{\circ}$ angle is reflected in a change in slope in the loaddisplacement results. In Figure 8, and subsequent figures, the crack path on the rear side is only shown when it differs from the crack path on the front side.

Crack growth from a $\left[45^{\circ} / 45^{\circ}\right]$ interface (Specimen $\left.45-i i\right)$ did not show clear or consistent crack branching behaviour, as shown in Figure 8(b). For this case, the crack grew within the $45^{\circ}$ plies and also sometimes along an adjacent $\left[45^{\circ} / 0^{\circ}\right.$ ] interface, with multiple crack paths. This is shown in Figure 9. Crack growth within $45^{\circ}$ plies in this manner was associated with much higher fracture toughness than crack growth along an interface, as seen in higher $G_{\text {avg }}$ values in Table 1.

Crack branching through $45^{\circ}$ plies was not shown to be influenced by delamination flaws along the initial interface, in the same way as for $90^{\circ}$ plies shown in Figure 6(b). Crack growth with this flaw configuration (Specimen 45 -iii) for a $\left[0^{\circ} / 45^{\circ}\right]$ interface did show rapid crack growth associated with the region of the delamination flaw, but the crack 
did not return to the original interface. This was also the case when the delamination flaw spacing was increased from $10 \mathrm{~mm}$ to $20 \mathrm{~mm}$ (Specimen 45-iv), or when delamination flaws at multiple ply interfaces were used (Specimen 45-v). So, delamination flaws were found to not be effective in controlling or directing the crack path for $45^{\circ}$ plies.

However, the use of a ply gap for a $0^{\circ}$ ply on the other side of a $45^{\circ}$ ply (Specimen 45-vi) was found to consistently cause crack branching through the $45^{\circ}$ ply. This is shown in Figure 8(c) and Figure 10, and demonstrates that crack branching through $45^{\circ}$ plies could be controlled by the stress concentration around the ply gap region caused by the termination of $0^{\circ}$ plies. For this to occur in a consistent manner, there needed to be sufficient spacing between the initial crack and the ply gap to allow for crack branching across the width of the specimen. Figure 10 shows a plan view of the lower crack surface for Specimen 45-vi, which shows the bottom ply (p) of the crack interface. This is complemented by images of the crack from the rear side. From this, the relationship between the crack path on the front and rear sides of the specimen can clearly be seen.

Crack branching was separately able to be demonstrated in a consistent manner through a $45^{\circ}$ ply using the branch flaw concept shown for $0^{\circ}$ plies in Figure 4(c), though as seen for the $0^{\circ}$ plies this resulted in a large drop in load as the crack passed through the branch flaw. This is demonstrated using the quasi-isotropic specimens in the following section. 


\subsection{Crack branching through a quasi-isotropic laminate}

Crack branching through quasi-isotropic laminates was investigated with specimens Q-i to Q-iii as shown in Table 1 and Figure 3. Typical aerospace quasi-isotropic laminates were investigated to demonstrate that the combination of crack growth outcomes of the previous sections could be used to control crack branching through a multi-directional laminate. This was achieved by controlling the crack to deflect away from the mid-plane through the various ply orientations towards the specimen outer surface. A first [45,0,45,90 $]_{2 S}$ laminate was investigated (Specimen Q-i), where crack branch flaws were used for $0^{\circ}$ and $45^{\circ}$ plies, and no flaws were used for $90^{\circ}$ plies. The results are shown in Figure 11(a), where this configuration was successful in demonstrating crack control, though the cracking through all the successive branch flaws caused a large drop in load. From the initial flaw, the crack branched through a $90^{\circ}$ ply away from the subsequent embedded flaws, but then branched back through two $90^{\circ}$ plies towards the embedded flaws. Crack branching then proceeded through each of the branch flaws, and the subsequent $90^{\circ}$ ply (ply 13).

A second $[45,0,-45,90]_{2 S}$ laminate was investigated (Specimen Q-ii) with less branch flaws, where branch flaws were only used through $0^{\circ}$ plies, but the capability of branch flaws to "attract" cracks through $45^{\circ}$ was relied on, with sufficient spacing to ensure branching across the width of the $\pm 45^{\circ}$ plies. The results are shown in Figure 11(b) and Figure 12, where crack growth was seen along the intended crack path for all instances. As with Specimen Q-i, some specimens showed initial crack propagation away from the embedded flaws through the $90^{\circ}$ ply (ply 8), though other specimens saw crack growth 
towards the embedded flaws (through ply 9). The crack then propagated along the intended path, where a branch flaw in a $0^{\circ}$ ply (ply 11) was sufficient to attract the crack through a preceding $-45^{\circ}$ ply (ply 10 ), and a delamination flaw between plies 13 and 14 was sufficient to attract the crack through a $45^{\circ}$ ply (ply 12). As with previous specimens, different crack paths were seen on front and rear sides. These aspects are further demonstrated using the plan view of the lower crack surface with rear side crack patterns shown in Figure 12. Furthermore, Figure 12 shows crack growth through $0^{\circ}, 45^{\circ}$ and $90^{\circ}$ plies, and as such is illustrative of the crack branching seen in all specimens.

Lastly, a different quasi-isotropic laminate $[45,90,-45,0]_{2 \mathrm{~S}}$ was investigated (Specimen Q-iii), with a different combination of embedded flaws, and the results (Figure 11(c)) again confirmed the crack control capability and single ply outcomes identified previously. The crack patterns and branching behaviour was similar to those shown in Figure 10 and Figure 12.

\section{Discussion}

The experimental results demonstrated that embedded flaws are able to control the crack path through quasi-isotropic ply orientations, and quasi-isotropic laminates. This approach has application to improve the damage tolerance of industrial structures, where a dangerous catastrophic failure could be controlled to become a safer and more progressive failure. To do this requires more detailed investigations into the extent to which the flaws have a deleterious effect on the properties of the laminate. For example, internal flaws such as those from manufacturing or from impact can have significant effect on strength, 
particularly for certain loading types such as compression or through-thickness shear [18]. Similarly, ply cuts have been investigated by several authors [13, 19], where the discontinuity in load-carrying fibres can lead to significant strength reductions. For all of these cases, identification of the minimum size for each flaw type is important, in order to identify the trade-off between crack control capabilities and other important properties. Similarly, the appropriate spacing between flaws is another important factor that requires further study, as the stress concentration at an embedded flaw can cause earlier crack growth or a significantly altered stress state relative to the intact case [13].

Despite this, there are several aspects that promote the application of this technology within industrial structures. Certification of aerospace structures requires demonstration of residual strength in the presence of flaws [20]. The typical flaws assumed in this process are those that can reasonably be expected to occur from either manufacturing or in-service damage. So, the assessment of flawed structures and the certification of flawed structures is standard practice, at least within aerospace, which demonstrates the maturity of such an approach. Also, strategic implementation of weak planes for increased safety is standard practice in crashworthiness design, where failure is typically localised to a damage mode of high energy absorbance [21]. Furthermore, the manufacturing process for large composite structures already introduces flaw-like features, such as where plies need to be terminated to change the laminate thickness, or where ply layers are necessarily discontinuous due to other manufacturing considerations [13]. This means that suitable flaws may already be unavoidably present within a composite structure, which suggests scope for synergistic application of the flaws as crack control devices. 
One other aspect that is relevant to crack control for improved fracture toughness is fibre bridging, where fibres remain connected across the crack face and increase the apparent fracture toughness of the interface [11, 14]. The occurrence of fibre bridging makes characterisation of fracture toughness more complex, as the degree of fibre bridging is dependent on many factors and difficult to isolate for a given specimen. Although the exact mechanisms are still subject to debate, it is clear that the apparent fracture toughness varies for different combinations of ply angles. For example, in this work, crack growth involving $45^{\circ}$ plies typically demonstrated the highest fracture toughness. So, for any given laminate, it should be possible to identify the interfaces or plies with highest fracture toughness, and to use crack control techniques to divert the crack to that location. Similarly, directing the crack away from areas of low toughness could be another application of using crack control for improved fracture toughness, though this would need to overcome the challenge of the energy minimisation principle. These aspects remain the topic of ongoing research activities.

\section{Conclusion}

The use of embedded flaws to control and direct interlaminar and through-thickness fracture was studied experimentally using Mode I crack growth specimens. Crack growth through $0^{\circ}$ plies could be controlled by using a crack branch flaw, though this did cause a significant drop in specimen load carrying. Crack branching through $90^{\circ}$ plies was seen without any flaws, but was able to be controlled using delamination flaws. Crack branching through $45^{\circ}$ plies was found to be controllable using ply gaps and crack branch flaws. Crack branching through two different quasi-isotropic laminates was demonstrated using 
different flaw configurations. The results suggest methods for improved damage tolerance and fracture toughness of composite structures.

\section{Acknowledgments}

The authors would like to thank Mr Robert Ryan and Mr Peter Tkatchyk of RMIT University for technical support in manufacture and testing. 


\section{References}

[1] Launey ME, Buehler MJ, Ritchie RO. On the mechanistic origins of toughness in bone. Annual Review of Materials Research. 2010;40:25-53.

[2] Ritchie RO. The conflicts between strength and toughness. Nature Materials. 2011;10:817-22.

[3] Chen P-Y, Lin AY-M, Lin Y-S, Seki Y, Stokes AG, Peyras J, et al. Structure and mechanical properties of selected biological materials. Journal of the Mechanical Behavior of Biomedical Materials. 2008;1:208-26.

[4] Meyers MA, Chen P-Y, Lin AY-M, Seki Y. Biological materials: Structure and mechanical properties. Progress in Materials Science. 2008;53:1-206.

[5] Malkin R, Trask RS, Bond IP. Control of unstable crack propagation through bioinspired interface modification. Composites Part A: Applied Science and Manufacturing. 2013;46:122-30.

[6] Demetriou MD, Launey ME, Garrett G, Schramm JP, Hofmann DC, Johnson WL, et al. A damage-tolerant glass. Nature Materials. 2011;10:123-8.

[7] Mirkhalaf M, Khayer Dastjerdi A, Barthelat F. Overcoming the brittleness of glass through bio-inspiration and micro-architecture. Nature Communications. 2014;5: 3166 doi: 10.1038/ncomms4166. 
[8] Bouville F, Maire E, Meille S, Van de Moortèle B, Stevenson AJ, Deville S. Strong, tough and stiff bioinspired ceramics from brittle constituents. Nature Materials. 2014;13:508-14.

[9] Barthelat F, Mirkhalaf M. The quest for stiff, strong and tough hybrid materials: an exhaustive exploration. Journal of the Royal Society Interface. 2013;10:1-8.

[10] Hull D, Shi YB. Damage mechanism characterization in composite damage tolerance investigations. Composite Structures. 1993;23:99-120.

[11] Andersons J, König M. Dependence of fracture toughness of composite laminates on interface ply orientations and delamination growth direction. Composites Science and Technology. 2004;64:2139-52.

[12] Krueger R, Cvitkovich MK, O'Brien TK, Minguet PJ. Testing and analysis of composite skin/stringer debonding under multi-axial loading. Journal of Composite Materials. 2000;34:1263-300.

[13] Malkin R, Yasaee M, Trask RS, Bond IP. Bio-inspired laminate design exhibiting pseudo-ductile (graceful) failure during flexural loading. Composites Part A: Applied Science and Manufacturing. 2013;54:107-16.

[14] Brunner AJ. Experimental aspects of Mode I and Mode II fracture toughness testing of fibre-reinforced polymer-matrix composites. Computer Methods in Applied Mechanics and Engineering. 2000;185:161-72. 
[15] de Morais AB, de Moura MF, Marques MF, de Castro PT. Mode-I interlaminar fracture of carbon/epoxy cross-ply composites. Composites Science and Technology. 2002;62:679-86.

[16] Pereira AB, de Morais AB. Mode-I interlaminar fracture of carbon/epoxy multidirectional laminates. Composite Science and Technology. 2004;64:2261-70.

[17] Fibre-reinforced plastic composites -- Determination of mode I interlaminar fracture toughness, GIC, for unidirectionally reinforced materials, ISO 15024:2001. International Standards Organisation; 2001.

[18] Robinson P, Greenhalgh ES, Pinho ST. Failure Mechanisms in Polymer Matrix Composites. Cambridge, UK: Woodhead Publishing Limited; 2012.

[19] Richards JM, Darby MI, Baggott R, Wostenholm GH, Yates B, Dorey G, et al. Effects of manufacturing defects on the mechanical properties of carbon fibre reinforced polyethersulphone laminates. Journal of Materials Science. 1984;24:584-9.

[20] Goh JY, Georgiadis S, Orifici AC, Wang CH. Effects of bondline flaws on the damage tolerance of composite scarf joints. Composites Part A: Applied Science and Manufacturing. 2013;55:110-9.

[21] Greer DL, Breeden JS, Heid TL. Crashworthy Design Principles. Federal Aviation Agency (FAA) Technical Report ADS-24, Washington, DC, USA; 1964. 
Table 1: Specimen configurations and results (coefficient of variation in parenthesis).

\begin{tabular}{|c|c|c|c|c|c|}
\hline Specimen & Layup & Flaw configuration & Spacing $(\mathrm{mm})$ & $G_{\text {init }}\left(\mathrm{J} / \mathrm{m}^{2}\right)$ & $G_{\text {avg }}\left(\mathrm{J} / \mathrm{m}^{2}\right)$ \\
\hline $0-\mathrm{i}$ & {$[0]_{14}$} & FC1: no flaw & & $353(7 \%)$ & $667(22 \%)$ \\
\hline 0 -ii & {$[0]_{14}$} & FC2: ply gap at ply 8 & $d=10$ & $381(6 \%)$ & $590(19 \%)$ \\
\hline 0 -iii & {$[0]_{14}$} & FC3: branch at ply 7-8 & $d=10$ & $509(28 \%)$ & $408(35 \%)$ \\
\hline 90-i & {$[0,90]_{7}$} & FC1: no flaw & & $106(11 \%)$ & $451(21 \%)$ \\
\hline 90 -ii & {$\left[90,0_{5}, 90\right]_{\mathrm{S}}$} & FC1: no flaw & & $71(38 \%)$ & $982(20 \%)$ \\
\hline 90-iii & {$[0,90]_{7}$} & FC4: delam at ply 7-8 & $d=10$ & $138(10 \%)$ & $387(26 \%)$ \\
\hline 90-iv & {$[0,90]_{7}$} & FC4: delam at ply 7-8 & $d=20$ & $175(46 \%)$ & $520(39 \%)$ \\
\hline $90-\mathrm{v}$ & {$\left[90,0_{5}, 90\right]_{\mathrm{S}}$} & FC5: delam at ply 6-7 and 8-9 & $d=10$ & $165(88 \%)$ & $603(55 \%)$ \\
\hline $45-i$ & {$[0,45]_{7}$} & FC1: no flaw & & $123(30 \%)$ & $1060(25 \%)$ \\
\hline 45-ii & {$\left[45,0_{5}, 45\right]_{\mathrm{s}}$} & FC1: no flaw & & $137(18 \%)$ & $1135(16 \%)$ \\
\hline 45-iii & {$[0,45]_{7}$} & FC4: delam at ply 7-8 & $d=10$ & $207(41 \%)$ & $1054(34 \%)$ \\
\hline 45-iv & {$[0,45]_{7}$} & FC4: delam at ply 7-8 & $d=20$ & $294(12 \%)$ & $1203(32 \%)$ \\
\hline $45-v$ & {$\left[45,0_{5}, 45\right]_{\mathrm{S}}$} & FC5: delam at ply 6-7 and 8-9 & $d=10$ & 227 (65\%) & $1010(41 \%)$ \\
\hline 45-vi & {$[45,0]_{7}$} & FC6: ply gap at ply 6 and 8 & $d=10$ & $834(5 \%)$ & $713(26 \%)$ \\
\hline Q-i & {$[45,0,-45,90]_{2 \mathrm{~S}}$} & $\begin{array}{l}\text { FC7: ply gap at plies } 10,11,12 \text {, } \\
14,15\end{array}$ & $d=10$ & $680(15 \%)$ & $272(70 \%)$ \\
\hline Q-ii & {$[45,0,-45,90]_{2 \mathrm{~S}}$} & $\begin{array}{l}\text { FC8: ply gap at ply 11; } \\
\text { delam at ply 9-10 and 13-14 }\end{array}$ & $\begin{array}{l}d_{1}=10 \\
d_{2}=20\end{array}$ & $716(11 \%)$ & $857(42 \%)$ \\
\hline Q-iii & {$[45,90,-45,0]_{2 \mathrm{~S}}$} & $\begin{array}{l}\text { FC9: ply gap at ply 9-10 and } \\
\text { 13; delam at ply } 15-16\end{array}$ & $\begin{array}{l}d_{1}=10 \\
d_{2}=20\end{array}$ & $266(23 \%)$ & $1173(59 \%)$ \\
\hline
\end{tabular}




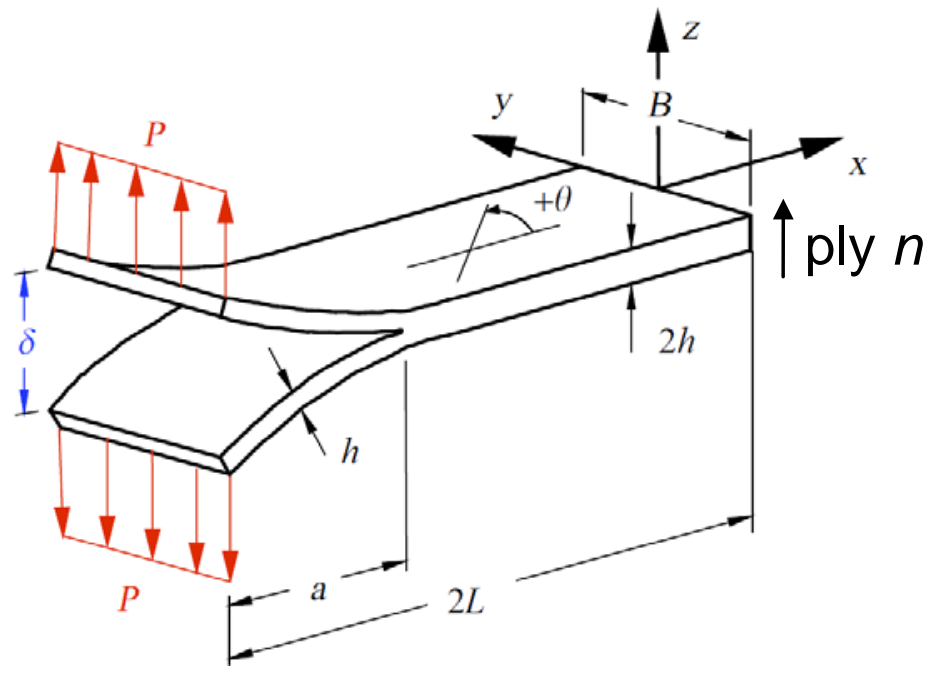

\section{B $20 \mathrm{~mm} \quad 2 L \quad 130 \mathrm{~mm}$ a $\quad 60 \mathrm{~mm}$}

Figure 1: DCB specimen geometry.
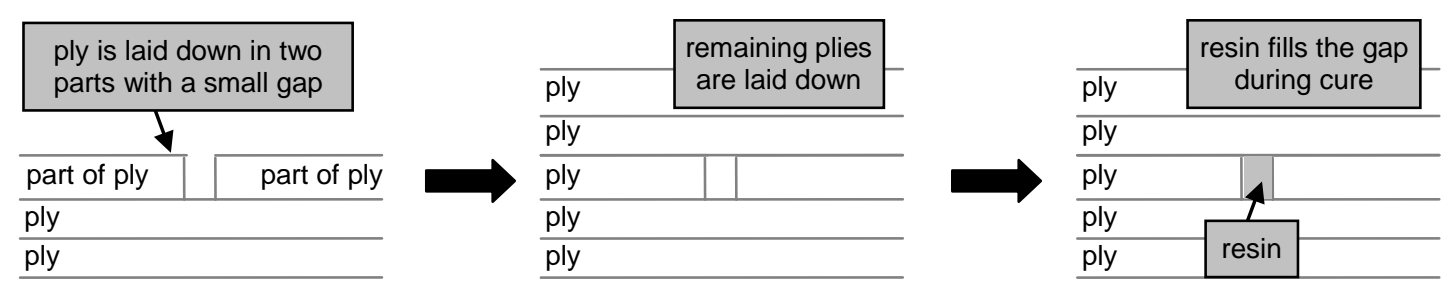

\section{ply gap}
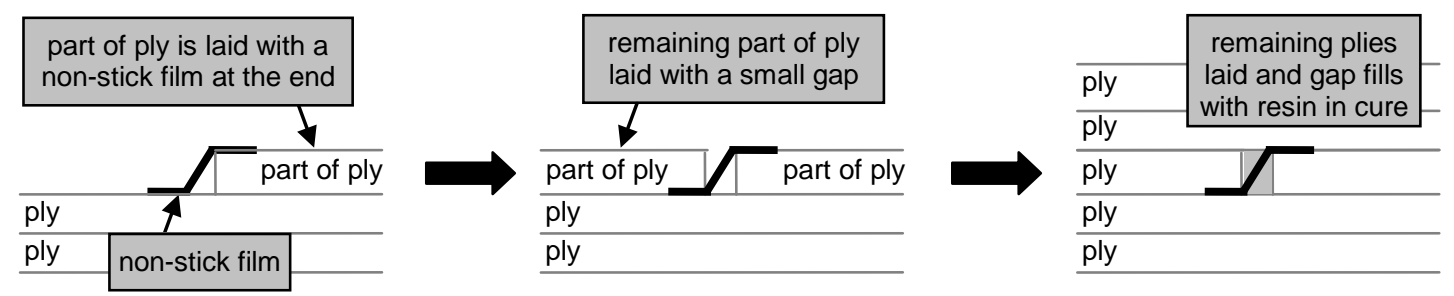

\section{branch flaw}

Figure 2: Procedure for creating ply gaps and branch flaws 


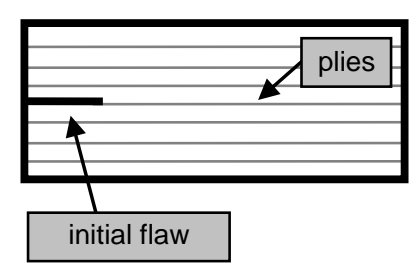

FC1

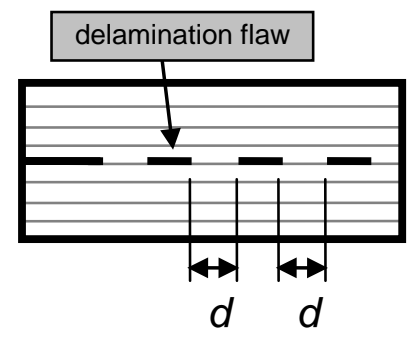

FC4

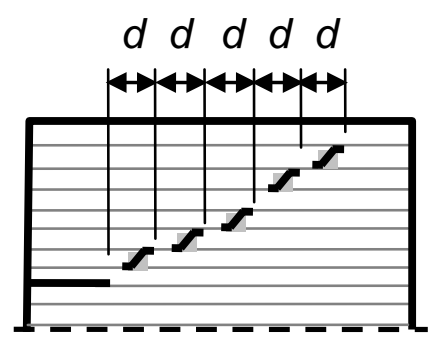

FC7

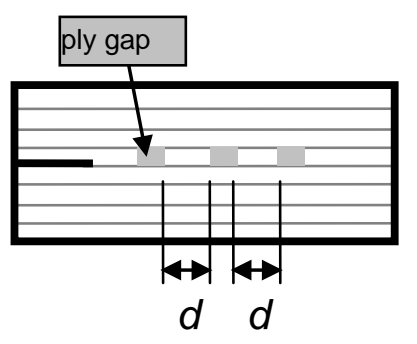

FC2

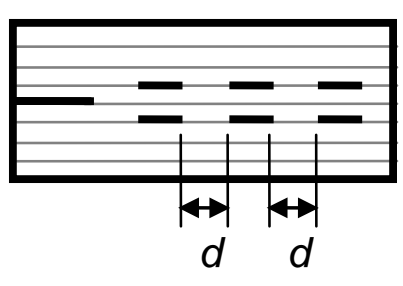

FC5

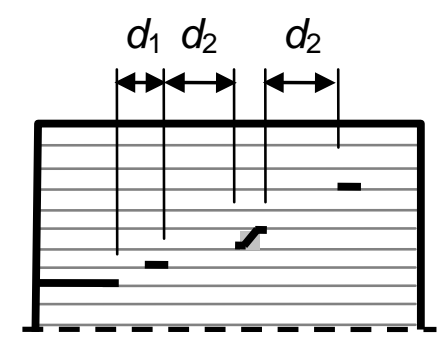

FC8

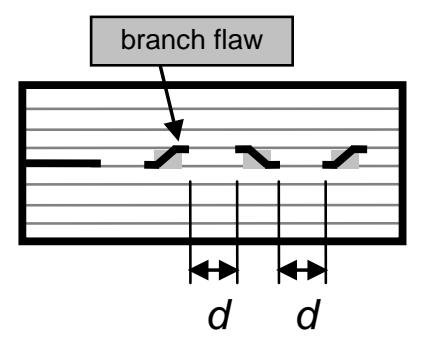

FC3

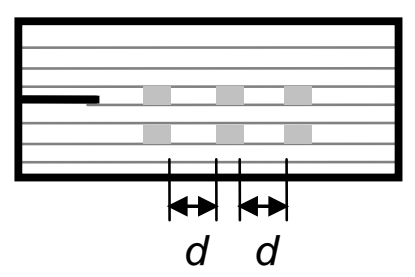

FC6

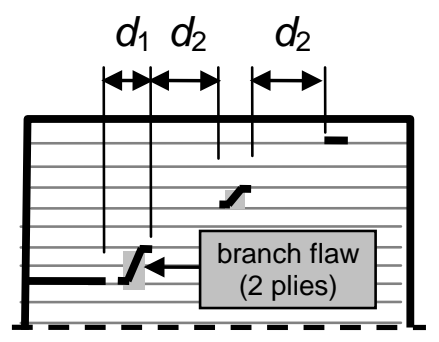

FC9

Figure 3: Specimen flaw configurations 

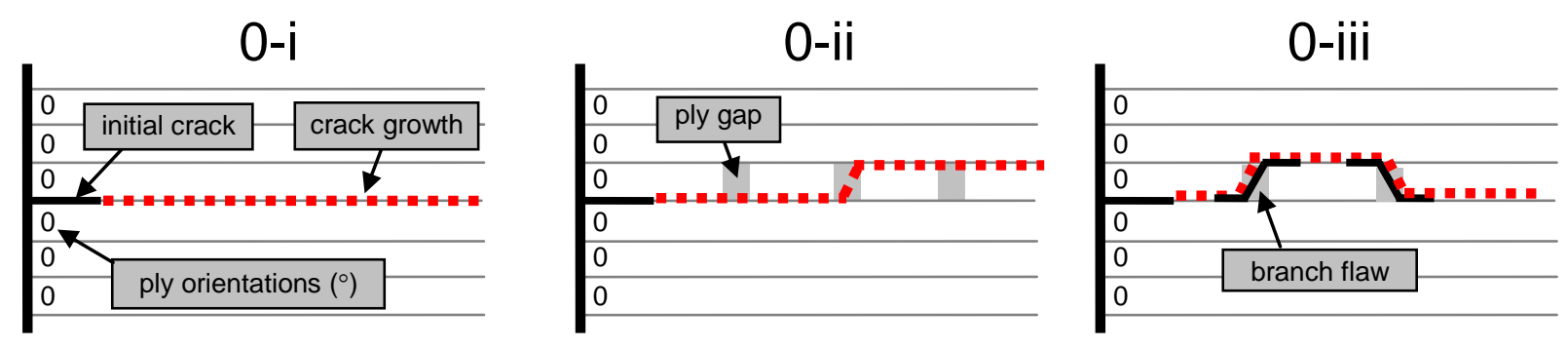

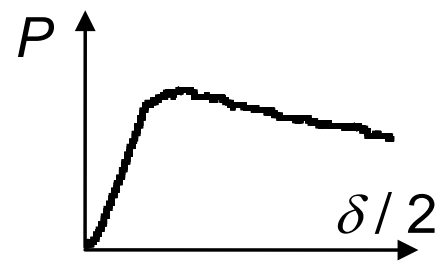

(a)

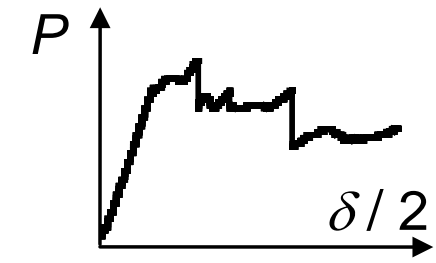

(b)

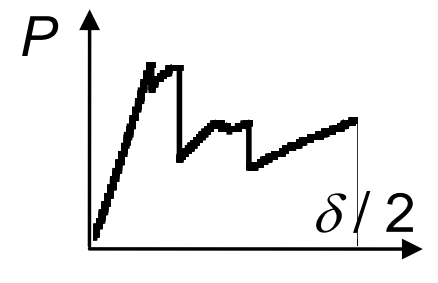

(c)

Figure 4: Crack growth results investigating branching through a $0^{\circ}$ ply

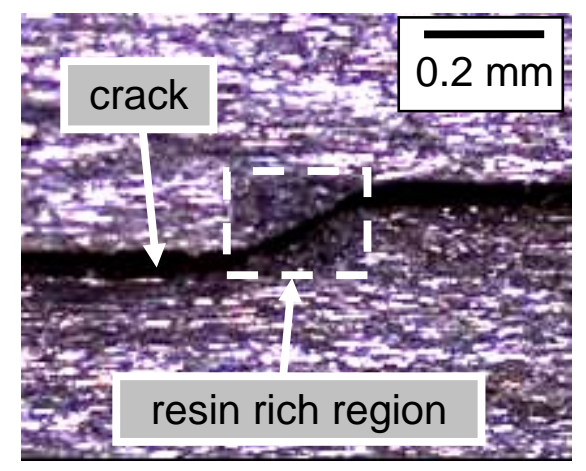

Figure 5: Crack branch flaw through $0^{\circ}$ plies (Specimen 0-iii) 

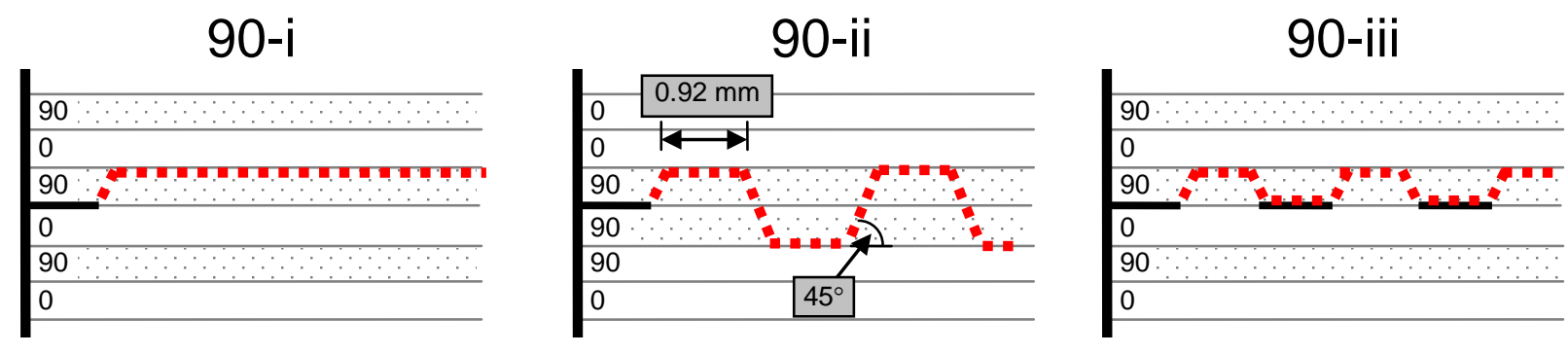

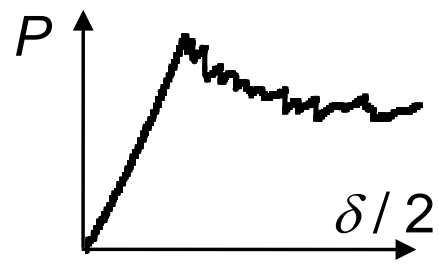

(a)

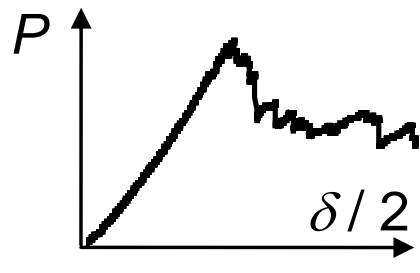

(b)

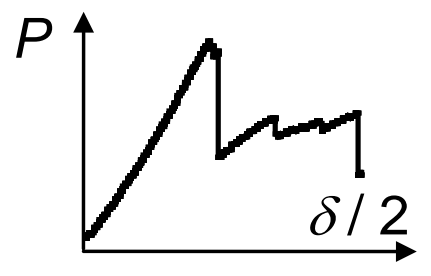

(c)

Figure 6: Crack growth results investigating branching through a $90^{\circ}$ ply

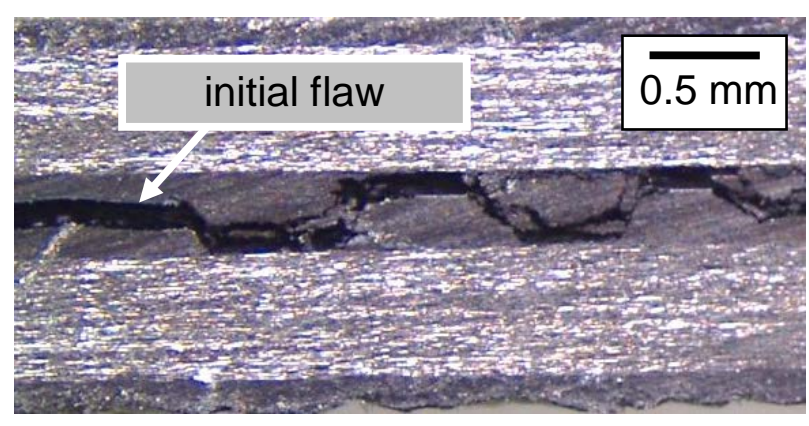

Figure 7: Crack growth zig-zag pattern through two $90^{\circ}$ plies (Specimen 90-ii) 

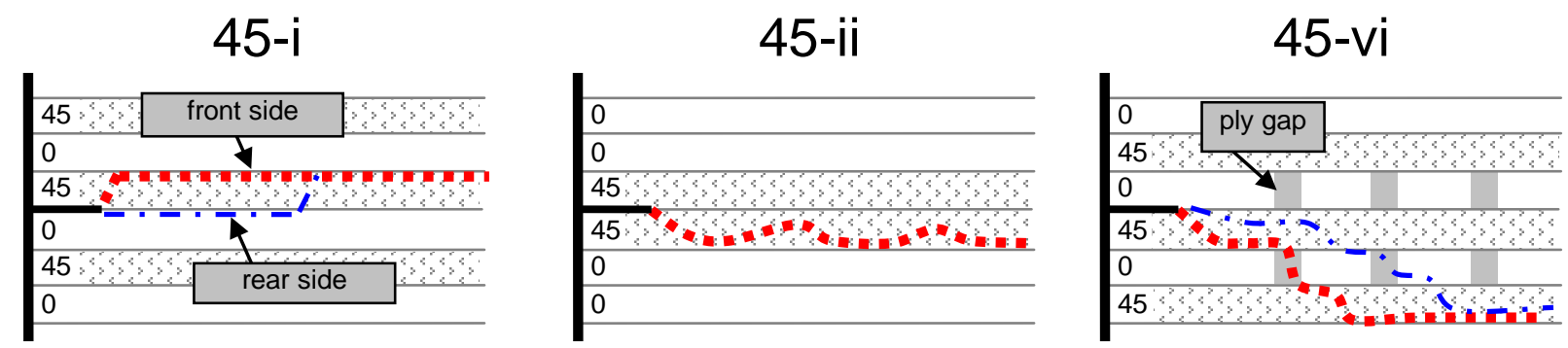

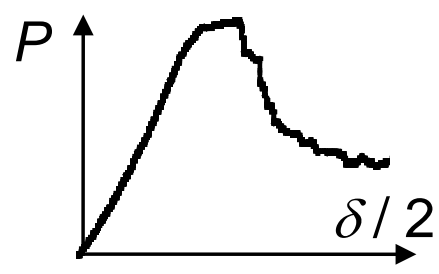

(a)

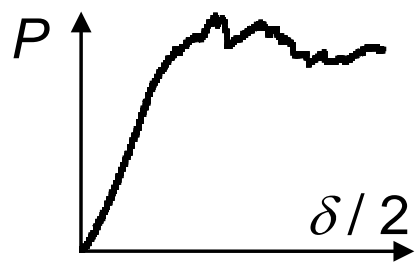

(b)

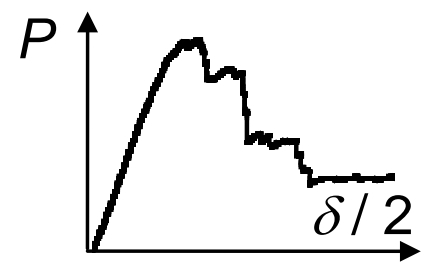

(c)

Figure 8: Crack growth results investigating branching through a $45^{\circ}$ ply

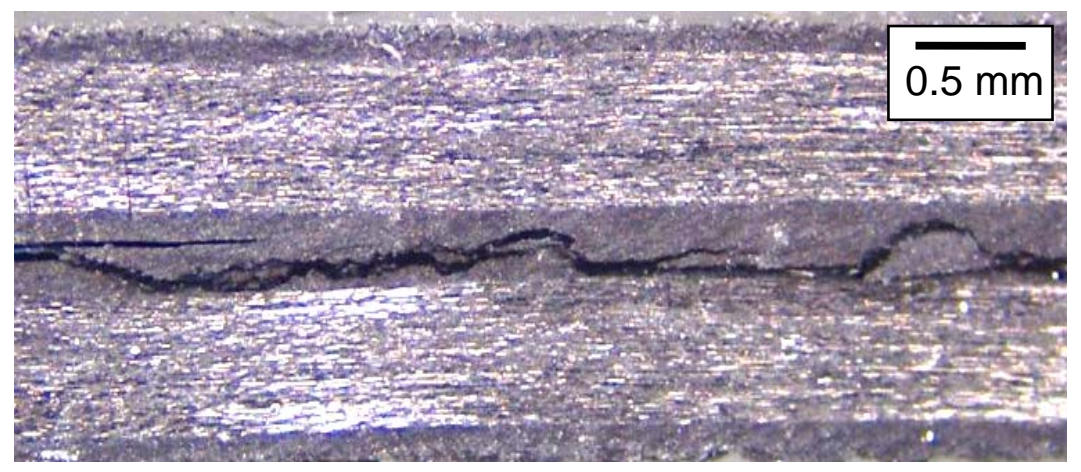

Figure 9: Multiple crack paths in two $45^{\circ}$ plies (Specimen 45 -ii) 


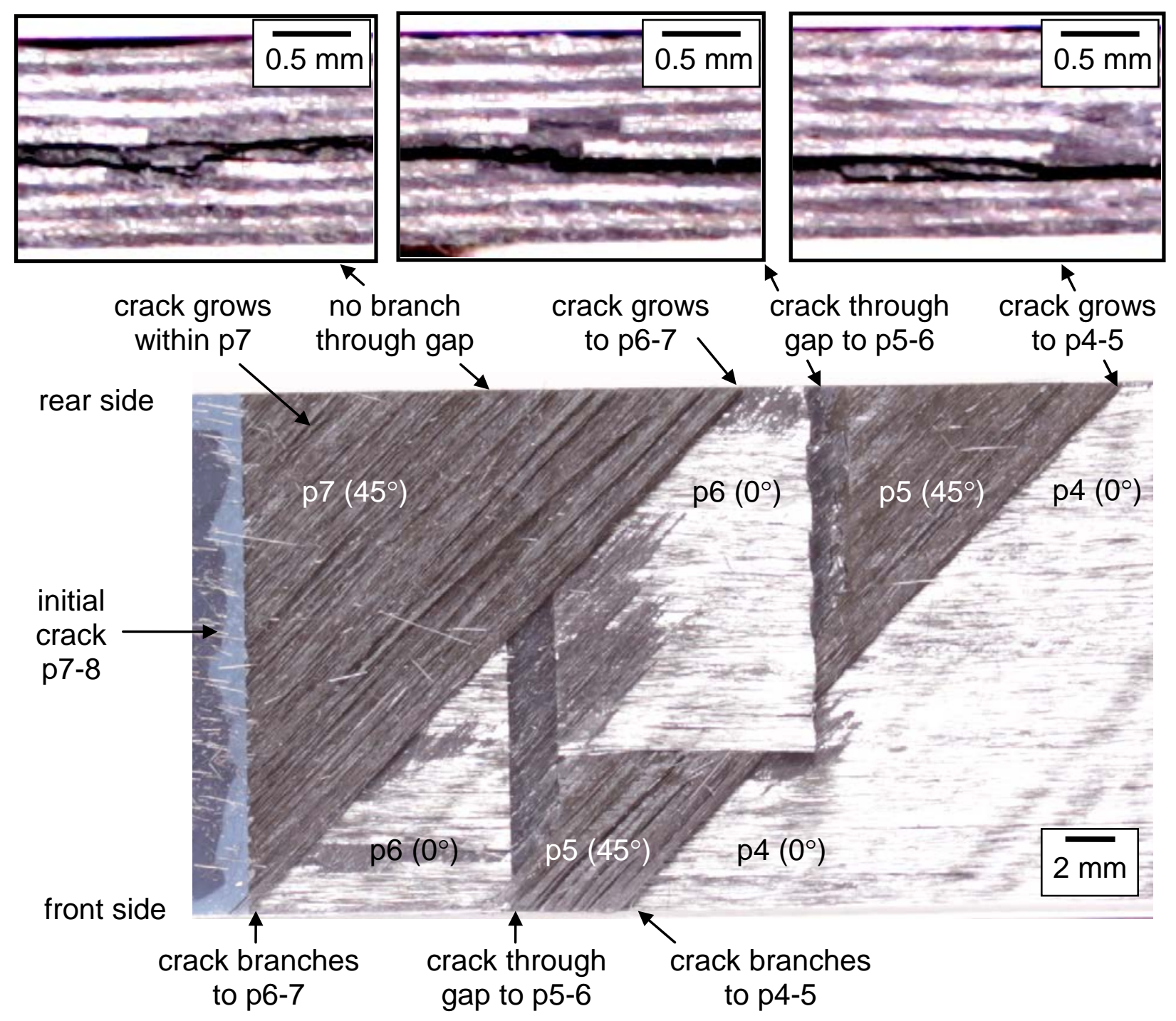

Figure 10: Crack branching through $45^{\circ}$ plies using ply gaps (Specimen $\left.45-v i\right)$. Lower image: Plan view of lower crack surface. Top row: Rear side views. See Figure 8(c) for schematic. 
(a)
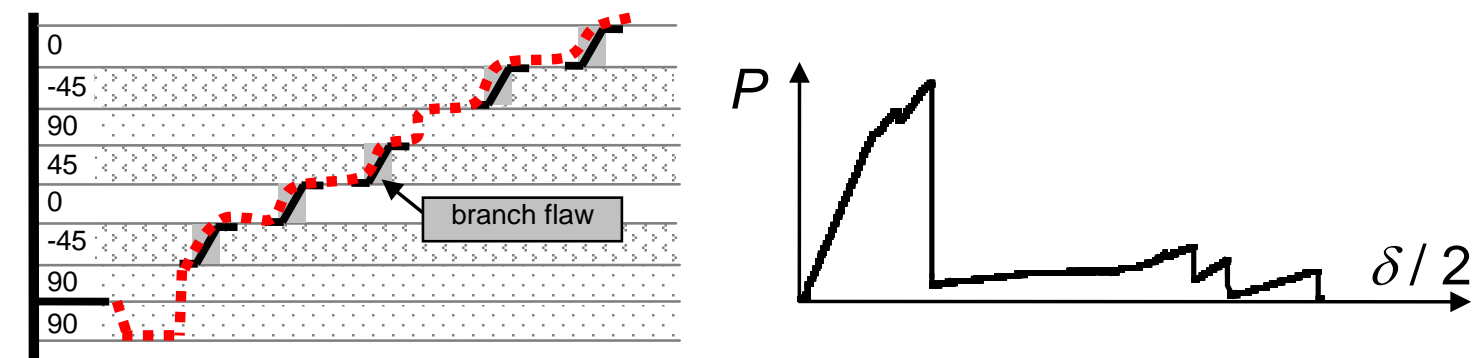

(b)
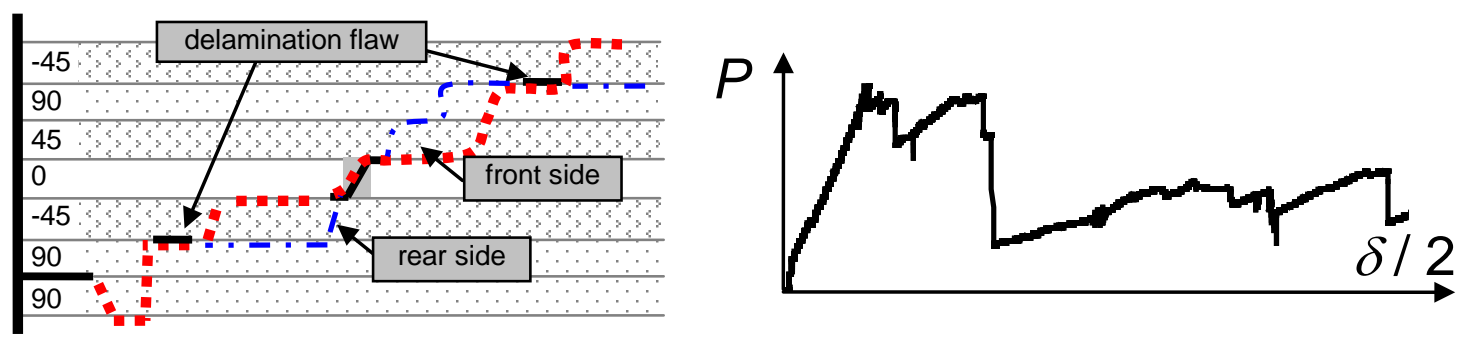

(c)
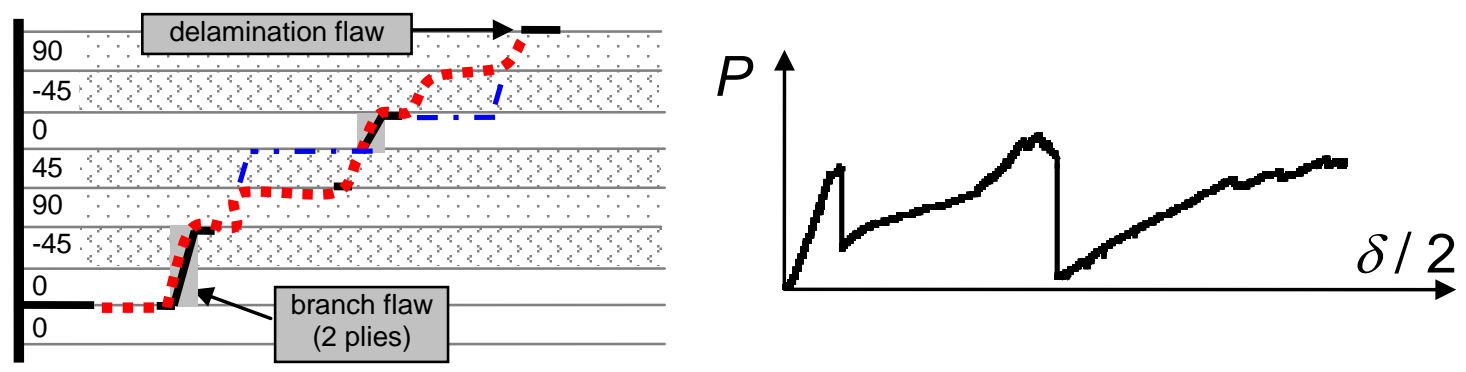

Figure 11: Crack growth results investigating branching through a quasi-isotropic laminate. (a) Specimen Q-i. (b) Specimen Q-ii. (c) Specimen Q-iii. 


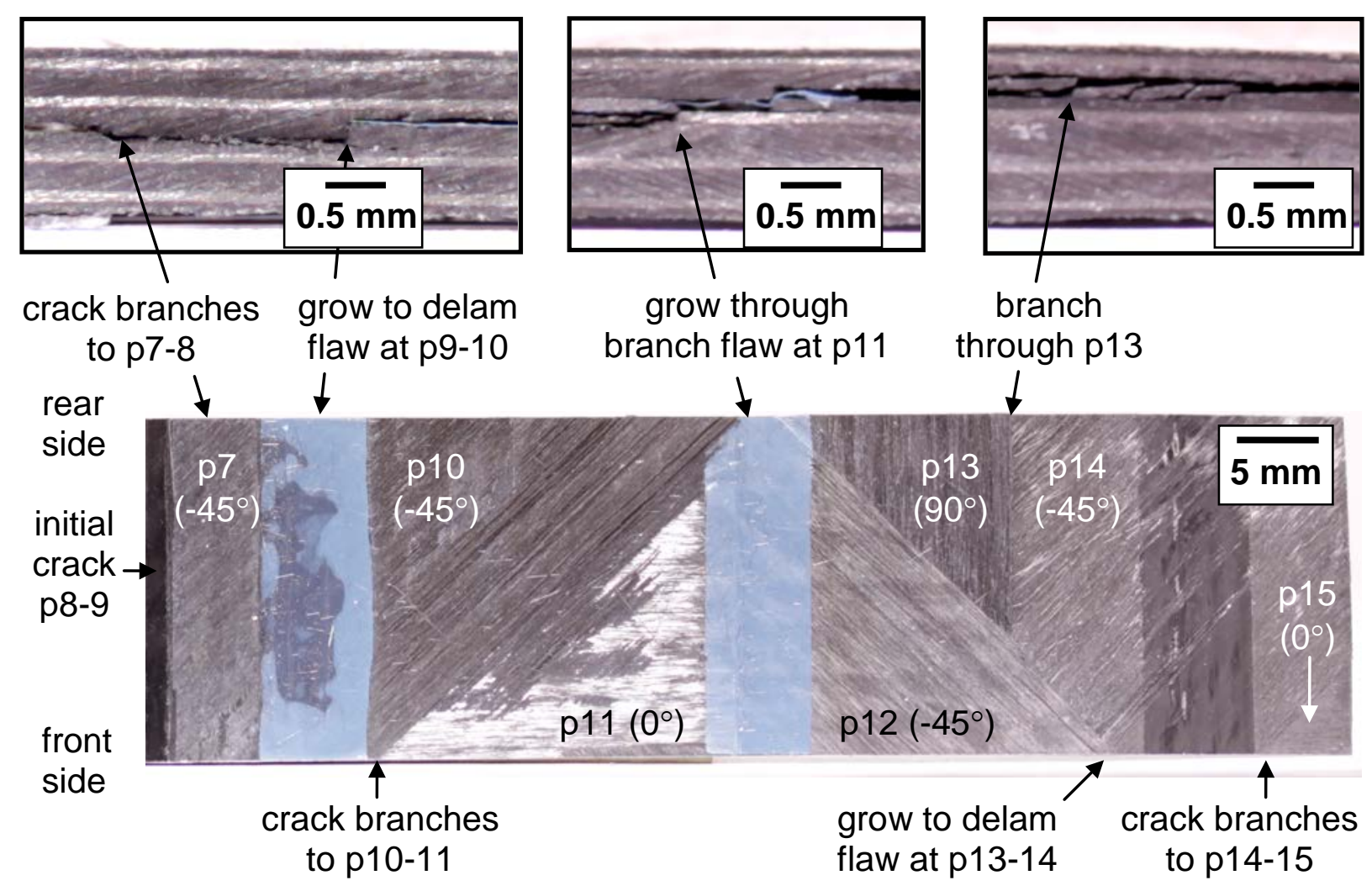

Figure 12: Crack growth through a quasi-isotropic laminate (Specimen Q-ii). Lower image: Plan view of lower crack surface. Top row: Rear side views. See Figure 11(b) for schematic. 